\title{
HEART DAMAGE FOLLOWING ADDER BITE IN ENGLAND
}

\author{
BY \\ ROBERT BROWN and H. A. DEWAR \\ From the Royal Victoria Infirmary, Newcastle upon Tyne
}

The common adder (Vipera berus) is the only indigenous poisonous snake in Britain, its venom is of relatively low toxicity, and death due to adder bite is rare in adults (Manson-Bahr, 1957). We report here a case of snake bite of extreme severity associated with a most unusual cardiac complication.

\section{Case History}

The patient, a fit 22-year-old ex-paratrooper, was invited to see a "grass-snake" that had been captured three days previously in the Cheviot Hills. Since capture, the snake had been kept without food or water in the warm cab of a lorry, and bit the patient on his left forefinger.

A few minutes later as the wound was being cleaned he noticed a light-headed sensation but feeling otherwise well he started walking to the nearest doctor's surgery. About 15 minutes later a passing motorist found him staggering along the road, stopped, helped him into his car, and brought him to the Royal Victoria Infirmary.

By the time he arrived at the hospital (approximately 30 minutes after the bite) he had developed abdominal colic. Later he started to vomit and become incontinent of large amounts of watery diarrhœa. About one hour after the bite his blood pressure fell to barely recordable levels and he lost consciousness. Intravenous normal saline with hydrocortisone and noradrenaline was started and about one and a half hours after the bite $15 \mathrm{ml}$. of anti-venomous serum (Pasteur Institute) was given after a negative test dose of $0.5 \mathrm{ml}$. the same evening. The snake, which had been killed and partly burned, was brought in and identified as an adder.

During the first 12 hours a total of 3 litres of normal saline, $500 \mathrm{ml}$. plasma, $300 \mathrm{mg}$. hydrocortisone, and $24 \mathrm{mg}$. noradrenaline were administered. His wound was dressed and intramuscular tetracycline started. Within one hour of admission the diarrhœa had stopped, the blood pressure rose to $100 / 60 \mathrm{~mm}$. $\mathrm{Hg}$, where it remained and he felt much better. Local reaction to the bite, however, increased and he developed an ascending lymphangitis with axillary lymphadenitis, increasing œdema, and ecchymosis. The œdema extended up into his neck and tongue and in an effort to prevent laryngeal odema chlorpheniramine (Piriton) $10 \mathrm{mg}$. intramuscularly was given every 8 hours with good effect.

Over the next 12 hours normal saline and 5 per cent dextrose were given alternately at a rate of 1 litre per 8 hours, and $1 \mathrm{mg}$. noradrenaline hourly was required to maintain his blood pressure at around 110/60 mm. Hg. He passed $900 \mathrm{ml}$. of urine during this period and serum electrolytes were as follows:

Sodium, $146 \mathrm{mEq} / 1$; potassium, $4.3 \mathrm{mEq} / 1$; chloride, $112 \mathrm{mEq} / 1$.; $\mathrm{CO}_{2}$ content, $23 \mathrm{mEq} / 1$; and blood urea, $58 \mathrm{mg} . / 100 \mathrm{ml}$.

This good progress was suddenly reversed about 30 hours after admission. The blood pressure fell in spite of increasing amounts of noradrenaline and the patient developed a rapid sinus tachycardia and eventually pulmonary œdema. He became unconscious again. With intravenous digoxin, chlorothiazide, approximately $200 \mu \mathrm{g}$. noradrenaline per minute, and $100 \mathrm{mg}$. of hydrocortisone he started to improve. This critical period lasted almost two hours.

The first electrocardiogram was taken during this period (Fig. 1A) and showed $T$ wave inversion in all standard leads, AVL, V5, and 6 with $0.5 \mathrm{~mm}$. S-T elevation in I and AVL. SGOT levels reached 106 units three days later and then fell to 30 units during the next five days. Following this episode improvement was maintained. The noradrenaline and the hydrocortisone were gradually withdrawn over the next 72 hours 


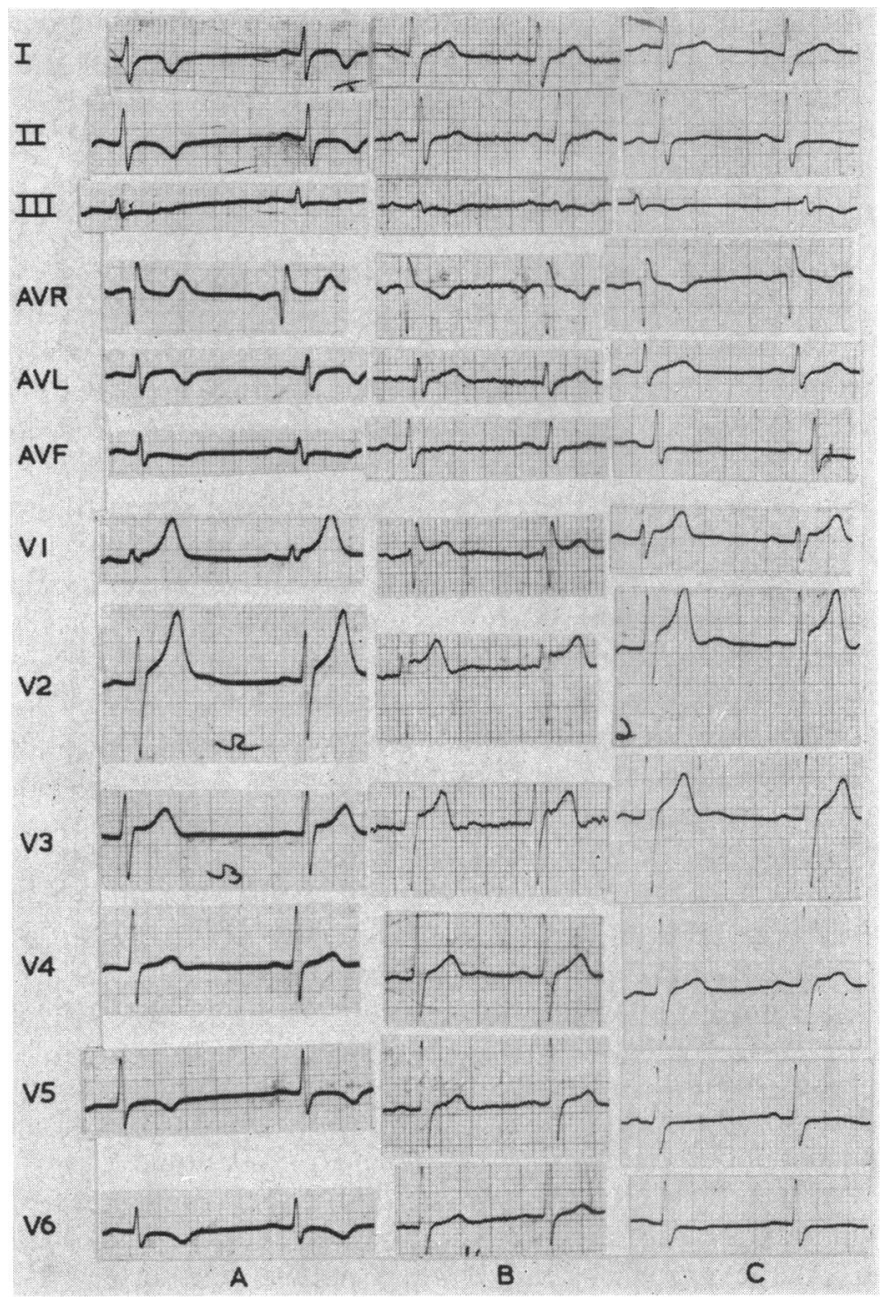

FIG. 1.-(A) Electrocardiogram following hypotensive episode. T waves in leads I, II, III, AVL, AVF, V5, and V6 are inverted and there is some S-T segment elevation in leads I, AVL, V1, V2, and V3. (B) Electrocardiogram three months later showing improvement. (C) Electrocardiogram during an attack of pain four and a half months after the snake bite. There is S-T segment depression in leads III and V6 with flattening of the T waves in V5 and V6.

and the digoxin stopped after five days. Alternate day electrocardiograms during the subsequent two weeks showed increasingly deep $T$ wave inversion in the same leads with reduction of the S-T elevation in I and AVL.

During early convalescence he had no cardiovascular symptoms and there were no abnormal physical signs. However, as he increased his activity he developed dyspnœea and definite angina of effort, relieved by glyceryl trinitrate. A chest radiograph at this time was normal. Over the succeeding three months the patient improved and the electrocardiographic changes became less marked (Fig. 1B).

About four and a half months after the bite the chest pain recurred. This time the patient experienced it also at rest in attacks lasting up to one hour. An electrocardiogram taken during one of these attacks showed a striking change with ST segment depression in leads III and V6, suggesting ischæmia (Fig. 1C). There was no increase of SGOT following this attack and his electrocardiogram returned toward normal.

He seemed to be experiencing ischæmic cardiac pain and because of his age and the possibility of a single 
coronary arterial obstruction which might be treated surgically it was decided to proceed with further investigations. He was referred to Dr. A. Leatham at St. George's Hospital, London, who arranged coronary angiography by selective catheterization of both coronary orifices. These appeared normal.

Since then the symptoms have disappeared and the patient is now earning his living by delivering $\frac{1}{2} \mathrm{cwt}$. bags of coal to a total of $10 \frac{1}{2}$ tons per day.

\section{Discussion}

In healthy adults the systemic reaction to adder bite is not in most cases severe. Where large amounts of venom are injected, however, extreme illness and occasionally death can occur(Walker, 1945; Morton, 1960). If the snake is prevented from hunting for food, and fluid is withheld, the quantity and concentration of the venom available for the next bite increase. In the present case the snake had been confined in a warm lorry cab without food and water for three days, so that it probably injected a heavy dose of its venom.

There is no doubt from the clinical, electrocardiographic, and serum transaminase findings that some form of myocardial damage resulted, directly or indirectly, from the bite and the electrocardiographic changes suggest that the area of damage was in the left ventricular wall. Pre-existing undiagnosed heart disease is extremely unlikely as the patient was a Territorial Army ex-paratrooper and had during the two weeks preceding this incident taken part in strenuous training manœuvres without chest pain or undue dyspnœa.

As to the nature of the muscle damage there are several possibilities. Some snake venoms are known to have direct injurious effects on heart muscle. Kellaway and Trethewie (1940) for example showed that cobra venom injected into a cat produced T wave inversion, A-V block, and eventually ventricular fibrillation; Reid et al. (1963) described "extensive and fluctuating $\mathrm{T}$ wave inversion in patients bitten by the Malayan pit viper (Ancistrodon rhodostoma), and Askanas (1959) mentioned areas of parenchymatous degeneration in the myocardium after lethal snake bite in a child. No such direct effect of adder bite has, however, been described.

Another possibility is that the venom caused thrombosis in or hæmorrhage from the coronary blood vessels. Some venoms, for instance that from Russell's viper, contain both coagulants with a predominantly local effect and anticoagulants (hæmorrhagins) with more systemic action, though Arneil and MacLaurin (1961) have described extensive thrombosis of the saphenous vein following an adder bite. In our patient ecchymosis of the upper arm was noted for some days following the injury, but there were no vascular effects elsewhere and it seems much more likely that the heart damage was associated with the profound dehydration and shock. These latter features may well have been due in part to the action of bradykinin, a polypeptide formed by the action of snake venom on plasma globulin (Rocha e Silva, Beraldo, and Rosenfeld, 1949). It causes spasm of smooth muscle and dilatation of vessels with hypotension (Lewis, 1961), though on the coronary circulation it widens the arteries so that flow through them is increased (Maxwell, Elliott, and Kneebone, 1962). The net effect, however, is severe hypotension and a reduced blood flow which might have caused coronary arterial or arteriolar thrombosis. Askanas (1959) postulated that this had occurred in his 50-year-old male patient who developed a posterior myocardial infarct after a snake bite. The angina that crippled our patient during the next three months also indicates that the blood supply to the heart muscle was impaired and the normal coronary angiograms obtained later suggest that this impairment was in the small branches rather than in the main trunks. Subsequent recovery has presumably resulted from collateral channels, and it has been remarkably complete.

\section{Summary}

A case of myocardial damage, probably infarction, following an adder bite in a young man is reported. Recovery has been complete. No previous published record of this complication as a result of snake bite in this country has been found.

We wish to thank Dr. A. G. Leatham and Dr. K. E. Jefferson of St. George's Hospital, London, for their help in investigating this case. 


\section{References}

Arneil, G. C., and MacLaurin, J. C. (1961). Case of adder-bite with thrombosis of the saphenous vein. Brit. med. J., $1,1587$.

Askanas, Z. (1959). Myocardial infarct in shock produced in snake bite. (In Polish.) Pol. Tyg. lek., 14, 1528.

Kellaway, C. H., and Trethewie, E. R. (1940). The liberation of adenyl compounds from perfused organs by cobra venom. Aust. J. exp. Biol. med. Sci., 18, 63.

Lewis, G. P. (1961). Bradykinin. Nature (Lond.), 192, 596.

Manson-Bahr, P. (1957). Snake-bite. Brit. med. J., 2, 468.

Maxwell, G. M., Elliott, R. B., and Kneebone, G. M. (1962). Effects of bradykinin on the systemic and coronary vascular bed of the intact dog. Circulat. Res., 10, 359.

Morton, T. C. (1960). Adder-bites in Cornwall. Brit. med. J., 2, 373.

Reid, H. A., Thean, P. C., Chan, K. E., and Baharom, A. R. (1963). Clinical effects of bites by Malayan viper (Ancistrodon rhodostoma). Lancet, 1, 617.

Rocha e Silva, M., Beraldo, W. T., and Rosenfeld, G. (1949). Bradykinin a hypotensive and smooth muscle stimulating factor released from plasma globulin by snake venoms and by trypsin. Amer. J. Physiol., 156, 261.

Walker, C. W. (1945). Notes on adder-bite (England and Wales). Brit. med. J., 2, 13. 